\title{
EFEK ANALISIS DAMPAK PEMBERLAKUAN PERMEN No. 71/PERMEN-KP/2016 TERHADAP KEBERADAAN JARING ARAD DI PERAIRAN TELUK JAKARTA
}

\author{
Handayani ${ }^{1)}$, Dwi Ernaningsih ${ }^{2)}$ \\ ${ }^{1,2)}$ Program Studi Pemanfaatan Sumberdaya Perairan FPIK USNI \\ Jl. Arteri Pondok Indah No. 11 Kebayoran Lama Jakarta 12240 \\ yanihandayani958@gmail.com,
}

\begin{abstract}
The aim of this research is to know the response of fisherman of arad nets towards the enactment of Regulation of Minister of Marine and Fishery Number 71 / PERMEN-KP / 2016, to analyze social, economic, and fishery resources impacts of Fishery Minister's Regulation No. 71 / PERMEN-KP / 2016 for fisherman nets Arad. This study used census method by conducting direct interviews to respondents using arad fishery fishing equipment which is represented by 30 arad fishermen respondents in Jakarta Bay waters (population). The results of this study for respondents who do not agree with the implementation of Candidate KP No. 71 Year 2016 argued that the arad web does not damage the aquatic ecosystem of the Bay of Jakarta, does not have the expertise to operate other fishing equipment other than arad nets, the absence of capital to replace the arad fishing gear, while for the respondents who agree with the enactment of Candidate KP. 71 of 2016 argued that the arad web was damaging the waters ecosystem of the Jakarta Bay so they were willing to switch to using environmentally friendly fishing gear. Social impact for fishermen of arad nets due to the enactment of Candidate of KP. 71 Year 2016 is the potential of social friction with other fishing gear. Impact is economy, fisherman's income arad net that will decrease drastically. The impact of the enactment of Candidate KP No. 71 Year 2016 to the fish resources there is a decrease in catches landed by fishermen nets arad so that fish resources can renew themselves, in addition to the aquatic ecosystem can improve themselves in order to create a well maintained ecosystem of fisheries.
\end{abstract}

Keywords: Permen KP No.71, Arad Jaring, Fishermen, Jakarta Bay 


\section{PENDAHULUAN}

\section{Latar Belakang}

Indonesia telah melangkah dari sekedar negara penghasil sumber daya perikanan menjadi negara yang memulai "best practices" dalam penegakan hukum perikanan dan pengelolaan yang bertanggung jawab. Setelah ikhtiar pemberantasan IUU fishing berhasil menumbuhkan efek jera (deterrent effect) dalam dua tahun terakhir ini, reformasi tata kelola perikanan dilakukan berdasarkan prinsip keberlanjutan (sustainability) daya dukung ekosistem. Dengan menegakkan kedaulatan dan menjaga keberlanjutan, peluang pengelolaan perikanan dalam mewujudkan kesejahteraan nelayan (prosperity) terbuka lebar. Saat ini, stok ikan semakin banyak, investasi asing di sektor penangkapan ikan juga telah ditutup. Nelayan Indonesia mulai dapat menikmati kekayaan laut Indonesia dan menjadi tuan di negeri sendiri setelah berpuluh-puluh tahun dijarah oleh kapal ikan asing melalui cara yang legal maupun ilegal. Untuk menjaga kontinuitas dari langkah-langkah perbaikan tata kelola pembangunan perikanan maka dibutuhkan payung hukum yang lebih kuat antara lain melakukan perbaikan terhadap Undang-Undang Perikanan agar sesuai dengan prinsip-prinsip kedaulatan, keberlanjutan, dan kesejahteraan, salah satunya adalah dengan menerbitkan peraturan perundang-undangan untuk menertibkan dan melarang alat penangkap ikan yang tidak ramah lingkungan dan dapat merusak kelestarian sumber daya perikanan dan ekosistem perikanan. Alat penangkap ikan yang dimaksud salah satunya adalah jaring arad.

Jaring arad merupakan salah satu alat penangkap yang ditujukan untuk menangkap udang. Jaring arad adalah alat tangkap yang dioperasikan secara aktif dengan cara ditarik oleh perahu. Hasil tangkapan alat tangkap jaring arad dapat dikategorikan ke dalam hasil tangkapan utama dan hasil tangkapan sampingan. Hasil tangkapan utama merupakan hasil tangkapan yang menjadi tujuan utama nelayan, sedangkan hasil tangkap sampingan merupakan tangkapan yang tidak sengaja tertangkap sewaktu alat tangkap jaring arad dioperasikan. Hasil tangkapan utama dari jaring arad ini adalah udang dan hasil tangkap sampingan berupa ikan-ikan demersal yang berukuran kecil seperti pepetek (Leiognathus $s p$ ), gulamah (Argyrosomus sp), beloso (Saurida tumbil), tigawaja (Pennahia argentata), pari (Himantura gerrardi), dan lain-lain.Mengacu pada Tatalaksana Perikanan yang Bertanggung Jawab (Code of Conduct for Responsible Fisheries) (FAO, 1995), permasalahan utama pada perikanan jaring arad adalah ketidakselektifan alat tangkap ini terhadap hasil tangkapan sehingga hasil tangkap sampingan (HTS) yang tertangkap jumlahnya jauh lebih besar dibandingkan dengan udang sebagai target spesies. Hasil tangkapan sampingan dari jaring arad ada yang dimanfaatkan dan ada juga yang dibuang ke laut baik dalam keadaan hidup atau mati. Proses pembuangan hasil tangkap sampingan dapat menyebabkan berkurangnya stok spesies target dan spesies non target yang memiliki nilai ekonomis serta dapat mengganggu proses ekologi di dasar perairan (Saila, 1983 diacu dalam Hall, 1999).

Sumber daya perikanan sebagai usaha milik bersama (common property) memungkinkan masuknya nelayan baru ke wilayah areal penangkapan ikan yang akan membuat intensitas penangkapan akan bertambah. Namun demikian, karena jumlah potensi perairan yang terbatas pada akhirnya akan menurunkan produksi 
hasil tangkapan per unit usaha. Untuk meningkatkan produksi, maka nelayan akan terus berusaha meningkatkan kapasitas penangkapan dengan menambah jumlah alat tangkap (Clark et al.,1985). Bila ini terjadi, maka penangkapan ikan secara berlebihan (biological overfishing) bisa saja terjadi secara bersama dengan kelebihan investasi (economic verfishing).

Skripsi ini dibuat untuk mengetahui dampak akibat pemberlakuan peraturan tentang Jalur Penangkapan Ikan dan Penempatan Alat Penangkapan Ikan di Wilayah Pengelolaan Perikanan Negara Republik Indonesia khususnya jaring arad yang berada di Teluk Jakarta. Hal ini didasari karena penggunaan alat tersebut dapat mengakibatkan kerusakan pada habitat ekosistem perikanan di Teluk Jakarta.

\section{Tujuan Penelitian}

a. Mengetahui respon nelayan jaring arad terhadap diberlakukannya Peraturan Menteri Kelautan dan Perikanan Nomor 71/Permen.KP/2016

b. Menganalisis dampak sosial, ekonomi, kelestarian sumber daya ikan diberlakukanya Peraturan Menteri Kelautan Perikanan Nomor 71/Permen.KP/2016 bagi nelayan jaring Arad.

\section{MATERI DAN METODE PENELITIAN}

\section{Waktu dan Tempat Penelitian}

Lokasi penelitan berada di sekitar Teluk Jakarta sedangkan pengumpulan data dilakukan di Tempat Pendaratan Ikan (TPI) di Cilincing Jakarta Utara dilaksanakan pada bulan Mei 2017.

\section{Alat dan Bahan}

Alat dan bahan yang digunakan dalam penelitian ini antara lain adalah :

a. Kamera

Kamera digunakan untuk mendokumentasikan kegiatan selama penelitian berlangsung.

b. Alat Tulis

Alat tulis digunakan untuk mencatat seluruh kegiatan dan data yang digunakan selama penelitian berlangsung.

c. Kapal Pengawas/Speedboat Pengawas Perikanan

Kapal Pengawas/Speedboat Pengawas Perikanan merupakan sarana untuk mengamati langsung kegiatan di lapangan (Perairan Teluk Jakarta)

d. Kuisioner

Media data primer yang dibutuhkan untuk dianalisis dalam penelitian ini.

e. Form Surat Pemeriksaan Kapal

Form Surat Pemeriksaan Kapal digunakan sebagai bahan acuan dalam memeriksa kapal perikanan.

\section{Metode Penelitian}

Penelitian dilakukan menggunakan metode sensus dengan melakukan wawancara langsung kepada responden yang menggunakan alat penangkap ikan jaring arad yang diwakili oleh 30 responden nelayan arad di Perairan Teluk Jakarta (populasi). 


\section{Analisis Data}

Data diperoleh dengan wawancara langsung dari nelayan jaring arad dan Kantor UPT Pangkalan PSDKP Jakarta yang berupa data penanganan pelanggaran kapal perikanan di wilayah perairan Teluk Jakarta. Data dibahas dan digambarkan dengan metode deskriptif yang akan mempermudah pembahasan karena metode ini membahas mengenai permasalahan, penanganan dan penyelesaian serta perkembangan dari suatu permasalahan.

Metode deskriptif adalah satu metode penelitian yang banyak digunakan pada penelitian yang bertujuan untuk menjelaskan kejadian. Penelitian deskriptif adalah sebuah penelitian yang bertujuan untuk memberikan atau menjabarkan suatu keadaan atau fenomena yang terjadi saat ini dengan menggunakan prosedur ilmiah untuk menjawab masalah aktual (Sugiyono, 2011).

\section{HASIL DAN PEMBAHASAN}

\section{Respon Nelayan Terhadap Pemberlakuan Peraturan Menteri Kelautan dan}

\section{Perikanan No. 71/PERMEN-KP/2016}

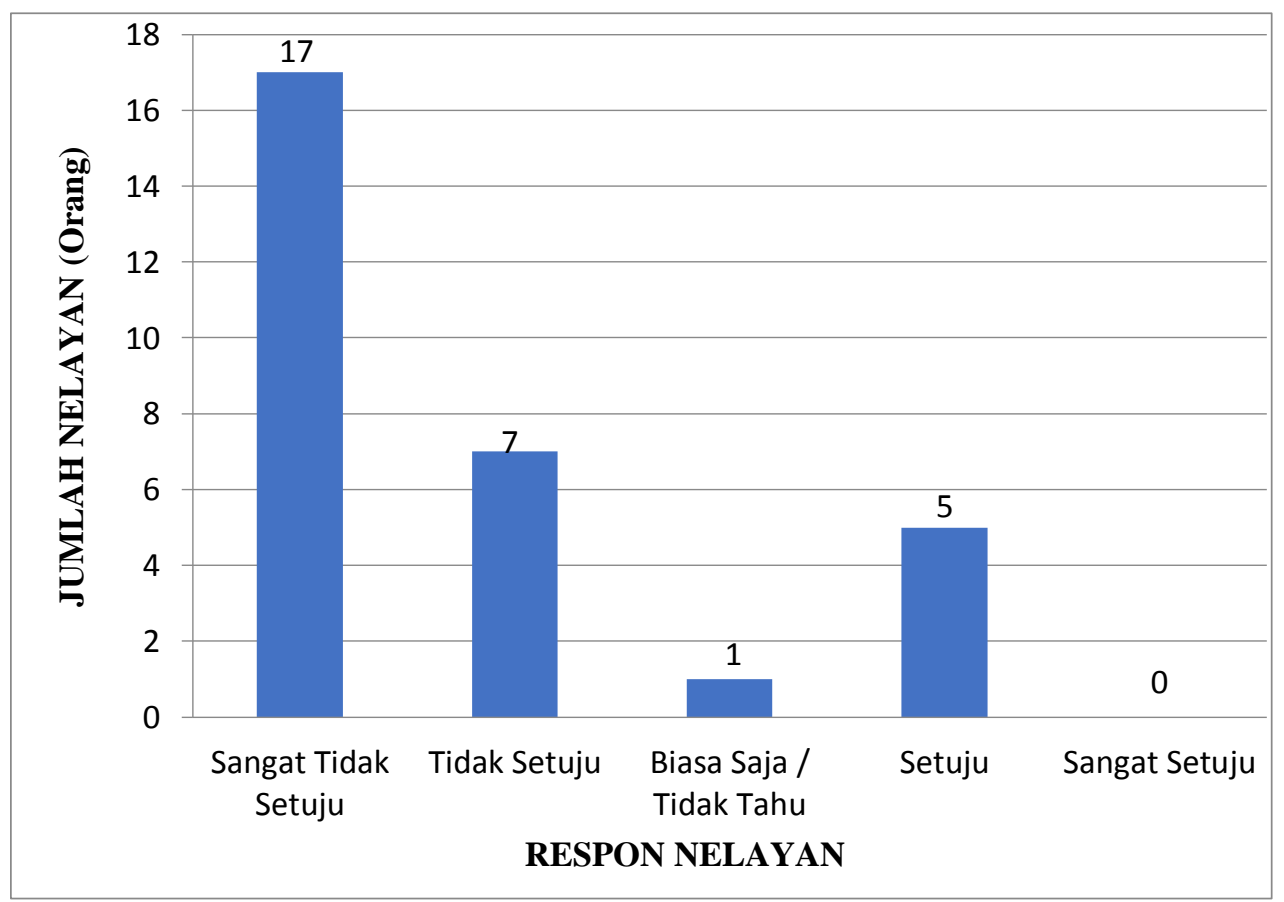

Gambar 1. Respon Nelayan Jaring Arad Terhadap PERMEN KP No. 71 Tahun 2016

Penelitian dilakukan untuk mengetahui dampak dari pemberlakuan permen KP No.71 Tahun 2016 terhadap populasi nelayan jaring arad di Perairan Teluk Jakarta. Berdasarkan metode sensus yang dilakukan terhadap responden (Gambar 1) didapat bahwa tujuh belas orang $(56,67 \%)$ responden sangat tidak setuju dengan pemberlakuan Permen KP No. 71 Tahun 2016. Sebanyak tujuh orang $(23,33 \%)$ responden tidak setuju dengan pemberlakuan Permen KP No. 71 Tahun 2016, satu orang $(3,33 \%)$ biasa saja/tidak tahu dengan pemberlakuan Permen KP 
No.71 Tahun 2016. Responden yang setuju dengan pemberlakuan Permen KP No.71 Tahun 2016 sebanyak lima orang $(16,67 \%)$ tidak ada responden yang sangat setuju terhadap pemberlakuan Permen KP No.71 Tahun 2016.

Didapatkan data sebanyak tujuh belas orang responden sangat tidak setuju dan tujuh orang responden tidak setuju dengan pemberlakuan Permen KP No.71 Tahun 2016 karena menurut responden, jaring arad tidak merusak ekosistem perairan Teluk Jakarta dan responden sebagian besar tidak memiliki keahlian menangkap ikan dengan menggunakan alat penangkap ikan lainnya selain jaring arad.

Sebanyak satu orang responden memilih biasa saja/tidak tahu terhadap pemberlakuan Permen KP No. 71 Tahun 2016 dan pada dasarnya responden tersebut setuju dengan pemberlakuan Permen KP No. 71 Tahun 2016 karena responden tersebut menyadari bahwa jaring arad merupakan alat penangkap ikan yang tidak ramah lingkungan yang dapat merusak ekosistem perairan dan alat tangkap tersebut bersifat tidak selektif, tetapi responden tersebut masih belum memiliki keahlian lain untuk menangkap ikan selain menggunakan jaring arad dan tidak memiliki modal yang cukup untuk melakukan transisi ke alat penangkap ikan lainnya yang ramah lingkungan.

Sebanyak lima orang responden setuju dengan diberlakukannya Permen KP No. 71 Tahun 2016 karena responden tersebut sudah menyadari sepenuhnya bahwa alat penangkap ikan jaring arad sangat tidak ramah lingkungan, dapat merusak ekosistem perairan dan bersifat tidak selektif terhadap hasil tangkapan yang terjaring. Responden tersebut bersedia mengganti alat penangkap ikan yang sekarang digunakannya yaitu jaring arad. Responden sangat mengharapkan bantuan dari pemerintah untuk memfasilitasi transisi dari jaring arad ke alat penangkap ikan yang ramah lingkungan, selain itu responden juga mengharapkan adanya bantuan dari pemerintah berupa bantuan modal usaha dikarenakan harga jaring arad yang relatif lebih murah dibandingkan dengan alat penangkap ikan lainnya yang ramah lingkungan.

\section{Dampak Sosial, Ekonomi, dan Kelestarian Sumber Daya Ikan Setelah}

\section{Diberlakukan Permen KP No. 71 Tahun 2016 Bagi Nelayan Jaring Arad}

\section{Dampak Sosial}

Informasi perbandingan hasil tangkapan jaring arad dengan alat penangkap ikan lainnya seperti dogol, payang, purse seine, dan tambak (TPI Cilincing). Hasil analisis yang didapat adalah bila dibandingkan hasil tangkapan jaring arad dengan alat penangkap ikan lainnya, dari tahun 2014 sampai dengan tahun 2016 hasil tangkapan jaring arad walaupun lebih banyak dibandingkan dengan alat penangkap ikan lainnya tetapi hasil tangkapan jaring arad mengalami penurunan yang sangat signifikan bila dibandingkan dengan alat tangkap lainnya. Alat penangkap ikan payang, dogol, purse seine, mengalami penurunan maupun kenaikan tetapi dengan selisih yang relative sedikit. Hal ini adalah akibat pengaruh dari implementasi Permen KP No. 71 Tahun 2017 terhadap jaring arad, sedangkan untuk alat penangkap ikan lainnya tidak terpengaruh implementasi Permen KP No. 71 Tahun 2016. 
Dampak sosial yang terjadi sebelum implementasi Permen KP No. 71 Tahun 2016 adalah rawan timbul gesekan antara nelayan jaring arad dengan alat penangkap ikan lainnya terkait jumlah hasil tangkapan yang didapat. Sesuai dengan karakteristik jaring arad yang tidak selektif, maka akan menyapu seluruh ikan yang dilewati oleh jaring tersebut ketika beroperasi. Berbeda dengan alat penangkap ikan lainnya yang lebih selektif sehingga hasil tangkapan yang didapat lebih terseleksi dan untuk masalah kuantitas akan berbeda lebih sedikit dibandingkan dengan jaring arad, sehingga rawan menimbulkan kecemburuan sosial terkait dengan hasil tangkapan ikan yang didapat.

Selain masalah selektifitas, operasional jaring arad yang ditarik atau dihela menggunakan kapal memiliki resiko lebih besar bersinggungan dengan nelayan yang menggunakan alat penangkap ikan lainnya karena jaring arad bisa saja merusak alat penangkap lainnya ketika alat atau jaring tersebut sedang disetting. Meskipun di wilayah penangkapan ikan di Teluk Jakarta nelayan yang menggunakan alat tangkap jaring arad dan nelayan yang menggunakan alat tangkap lain rawan terjadi gesekan, tidak terlihat adanya permusuhan antara nelayan yang menggunakan alat tangkap jaring arad dengan nelayan yang menggunakan alat tangkap lain, hal ini dimungkinkan karena nelayan berasal dari satu wilayah tempat tinggal yang sama.

\section{Dampak Ekonomi / Hasil Tangkapan}

Berdasarkan data sekunder (ikan yang didaratkan di TPI Cilincing) yang didapat dari Tempat Pelelangan Ikan (TPI) Cilincing, pada tahun 2014 nelayan jaring arad mendaratkan hasil tangkapan berupa ikan ke TPI cilincing sebanyak $312.643 \mathrm{~kg}$.

Penurunan jumlah hasil tangkapan jaring arad dari tahun 2014 sampai dengan tahun 2016. Hal ini disebabkan oleh :

a. Pada tahun 2014 sampai dengan tahun 2015 hasil tangkapan dari jaring arad mengalami penurunan dikarenakan jaring arad termasuk ke dalam klasifikasi trawl yang sejak tahun 1986 dilarang beroperasi di seluruh perairan Indonesia oleh karena itu nelayan arad melakukan operasional penangkapan ikan secara sembunyi-sembunyi dari aparat penegak hukum sehingga hasil tangkapan yang didapat tidak maksimal.

b. Terjadi penurunan hasil tangkapan yang sangat signifikan antara tahun 2015 sampai dengan tahun 2016 diakibatkan pemberlakuan Permen KP No. 71 Tahun 2016 sehingga aparat penegak hukum di laut melaksanakan pengawasan secara besar-besaran dan menyuluruh sehingga yang terjadi adalah banyak dari nelayan jaring arad yang tertangkap dan alat penangkap ikannya disita oleh aparat penegak hukum. Hal tersebut berdampak munculnya efek jera bagi nelayan tersebut dan nelayan jaring arad mulai untuk memikirkan mengganti alat penangkap ikan yang sekarang digunakan menjadi alat penangkap ikan yang ramah lingkungan. 


\section{Hasil Tangkapan Jaring Arad 2014-2016}

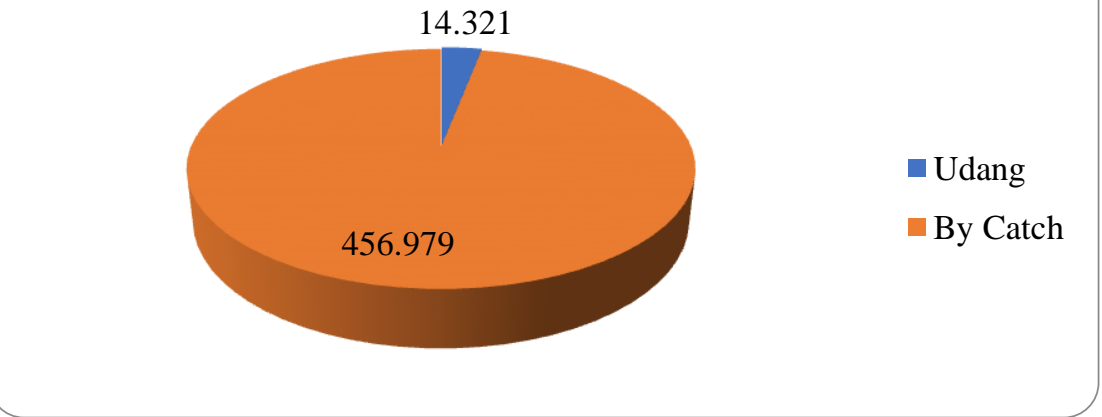

Gambar 2. Perbandingan Hasil Tangkapan Utama dan Sampingan Jaring Arad

Tahun 2014-2016

Berdasarkan diagram pada Gambar 2 di atas, didapat pula bahwa hasil tangkapan utama jaring arad perbandingannya dari tahun 2014 hingga tahun 2016 selalu lebih kecil bila dibandingkan dengan hasil tangkapan sampingan. Hasil tangkapan utama jaring arad yang berupa udang-udangan hanya sebesar $14.321 \mathrm{~kg}$ $(3,04 \%)$ padahal hasil tangkapan utama jaring arad merupakan ikan dengan nilai ekonomis tinggi bila dibandingkan dengan ikan-ikan yang berupa hasil tangkapan sampingan jaring arad. Hal ini dapat berakibat dengan menurunnya pendapatan dari nelayan jaring arad yang berdampak pada kondisi ekonomi dari nelayan jaring arad itu sendiri.

Pendapatan nelayan jaring arad dari 30 responden didapatkan informasi bahwa pendapatan paling rendah dari nelayan jaring arad adalah Rp 1.440.000 dan pendapatan paling tinggi selama sebulan adalah $\mathrm{Rp}$ 3.750.000. Pendapatan nelayan tersebut bersifat kotor dan belum dikurangi oleh kebutuhan sehari-hari selama 1 bulan. Upah Minimum Regional DKI Jakarta adalah Rp 3.350.000. Dari data pendapatan nelayan jaring arad, hampir 90\% atau sekitar 27 orang responden berada di bawah UMR DKI Jakarta. Hal ini berarti sebagian besar nelayan hidup dengan taraf kurang dari cukup.

Pemberlakuan Permen KP No. 71 Tahun 2016 berdampak terhadap pendapatan nelayan jaring arad. Hal ini terjadi karena adanya pengawasan yang dilakukan oleh pemerintah sehingga nelayan jaring arad beroperasi dengan cara sembunyi-sembunyi dari aparat penegak hukum di laut dan tidak dapat menghasilkan hasil tangkapan yang optimal. Selain faktor pengawasan, faktor overfishing juga berpengaruh terhadap hasil tangkapan jaring arad. Kondisi perairan Teluk Jakarta yang overfishing menyebabkan hasil tangkapan semakin hari semakin berkurang.

Hal ini berakibat dengan berkurangnya daya beli dari nelayan jaring arad. Untuk memenuhi kebutuhan dengan standar upah di bawah UMR DKI Jakarta sangat berat untuk dipenuhi nelayan jaring arad. Akibat dari hal tersebut, berdampak terhadap pemenuhan kebutuhan primer yang tidak tercukupi, pendidikan anak yang terpinggirkan, kesehatan yang tidak diperhatikan, dan berefek kepada dampak sosial. 
Pendapatan rata-rata nelayan jaring arad dari tahun 2014 sampai dengan 2016 mengalami penurunan. Pada tahun 2014 pendapatan rata-rata nelayan jarring arad mencapai Rp 3.530.000 sedangkan pada tahun 2015 terjadi penurunan pendapatan rata-rata nelayan jaring arad sebesar Rp 240.000 menjadi Rp 3.310.000 atau turun sebesar 6,79\%. Setelah diberlakukannya Permen KP No.71 Tahun 2016 terjadi penurunan yang sangat signifikan terhadap pendapatan ratarata nelayan jaring arad sebesar Rp 720.000 menjadi Rp 2.590.000 atau terjadi penurunan sebesar 21,75\%. Dapat diketahui bahwa Permen KP No. 71 Tahun 2016 mempengaruhi pendapatan nelayan jaring arad.

\section{Dampak Kelestarian Sumber Daya Ikan}

Adapun dampak sebelum dan sesudah Permen No. 71/Permen-KP/2016 diberlakukan :

$>$ Sebelum Permen KP No.71 Tahun 2016 diberlakukan

- Hasil tangkapan jaring arad semakin hari semakin menurun, diakibatkan kondisi selektivitas dari jaring arad tidak selektif, menangkap hampir semua jenis dan ukuran ikan yang dilalui atau disapu oleh jaring arad baik itu di kolom perairan atau di dasar perairan. Atas dasar hal tersebut, maka semakin lama perairan di suatu wilayah akan mengalami keadaan overfishing.

- Dengan adanya nelayan yang menggunakan alat tangkap jaring arad diwilayah tangkapan nelayan di teluk Jakarta, secara langsung akan berpengaruh terhadap ekosisitem diwilayah tangkapan tersebut. Jika terumbu karang terkena jaring arad akan mengalami kerusakan, begitu juga dengan ekosistem didasar perairan seperti ikan kecil, udang, kepiting, kerang, dll akan tertangkap oleh alat tangkap jaring arad, sehingga populasi biota laut baik didasar perairan maupun dipermukaan diwilayah teluk Jakarta akan mengalami penurunan semakin hari semakin menurun, yang dikemudian hari akan berdampak pada hasil tangkapan nelayan diwilayah teluk Jakarta.

- Berdasarkan data hasil tangkapan jaring arad dari tahun 2014 sampai dengan tahun 2016 sampai dengan saat ini semakin berkurang hasil tangkapan jaring arad, hal tersebut dikarenakan elemen pengawasan di laut yang sudah mulai digalakkan untuk menghilangkan alat penangkap ikan yang dilarang.

- Akibat alat tangkap jaring arad yang tidak selektif, maka jaring arad akan menyapu seluruh hasil tangkapan yang dilaluinya sehingga mendapatkan hasil tangkapan yang sangat banyak. Atas dasar hal tersebut, maka produktivitas jaring arad menjadi tidak terkontrol.

> Setelah diberlakukannya Permen KP No. 71 Tahun 2016

- Berdasarkan data yang didapat memang tidak ada peningkatan yang signifikan hasil tangkapan alat penangkap ikan yang ramah lingkungan, tetapi hasil tangkapan mengalami peningkatan jika dibandingkan dengan tahuntahun sebelumnya.

- Dengan tidak beroperasinya alat tangkap jaring arad akan mulai terlihat adanya perubahan populasi beberapa biota laut diwilayah tangkapan teluk jakarta karena beberapa ikan kecil, udang, kepiting, dll tidak tertangkap oleh nelayan jaring arad sehingga populasi beberapa jenis ikan tertentu secara berlahan akan bertambah.

- Secara otomatis akan melindungi ekosistem kerusakan terumbu karang di wilayah Teluk Jakarta. 
- Hal ini mengindikasikan bahwa sumber daya ikan yang bersifat dapat diperbaharui sudah mengalami proses restocking awal yang dapat membuat kondisi sebuah perairan menjadi kaya akan jenis dan jumlah ikan. Keadaan seperti ini karena semakin berkurangnya jaring arad yang beroperasi, yang mengeruk semua jenis dan ukuran ikan baik itu ikan besar maupun ikan-ikan kecil yang belum siap konsumsi

- Dengan berkurangnya jaring arad yang beroperasi, keadaan habitat ikan di Perairan Teluk Jakarta dapat memperbaiki diri sendiri karena efek hancurnya karang akibat tersapu jaring arad menurun.

- Pasca penegakan hukum di tengah laut dilakukan dengan ketat, maka nelayan jaring arad mulai tidak leluasa dalam beroperasi sehingga menurunkan hasil tangkapan yang didapat. Hal ini secara tidak langsung berdampak kepada menurunnya jumlah produksi ikan dari jaring arad sehingga dalam jangka panjang sumber daya ikan akan terperbaharui.

\section{KESIMPULAN DAN SARAN}

\section{Kesimpulan}

Kesimpulan yang didapat dari penelitian tentang analisis dampak pemberlakuan Peraturan Menteri Kelautan dan Perikanan Nomor 71/PERMENKP/2016 terhadap keberadaan jaring arad di Perairan Teluk Jakarta adalah sebagai berikut :

a. Responden yang tidak setuju dengan pemberlakuan Permen KP No. 71 Tahun 2016 beralasan :

$>$ Jaring arad tidak merusak ekosistem perairan Teluk Jakarta.

$>$ Tidak memiliki keahlian mengoperasikan alat penangkap ikan lainnya selain jaring arad.

$>$ Tidak adanya modal untuk mengganti alat penangkap ikan jaring arad.

Sedangkan untuk responden yang setuju dengan pemberlakuan Permen KP No. 71 Tahun 2016 beralasan :

$>$ Jaring arad merusak ekosistem perairan Teluk Jakarta sehingga mereka bersedia untuk beralih menggunakan alat penangkap ikan yang ramah lingkungan.

b. Dampak sosial bagi nelayan jaring arad akibat pemberlakuan Permen KP No. 71 Tahun 2016 adalah potensi gesekan sosial dengan nelayan alat tangkap lain, selain dampak sosial adalah ekonomi, pendapatan nelayan jaring arad yang akan menurun drastis.

c. Dampak pemberlakuan Permen KP No. 71 Tahun 2016 terhadap sumberdaya ikan terjadi penurunan hasil tangkapan yang didaratkan oleh nelayan jaring arad sehingga sumber daya ikan dapat memperbaharui diri, selain itu ekosistem perairan pun dapat memperbaiki diri agar tercipta ekosistem perikanan yang terjaga dengan baik.

\section{Saran}

Saran peneliti pada penelitian tentang analisis dampak pemberlakuan Peraturan Menteri Kelautan dan Perikanan Nomor 71/PERMEN-KP/2016 terhadap keberadaan jaring arad di Perairan Teluk Jakarta adalah sebagai berikut : 
a. Adanya BED (By Catch Excluder Device) pada jaring arad untuk menyeleksi hasil tangkapan sampingan yang belum layak tangkap.

b. Adanya sosialisasi dari Pemerintah kepada nelayan terkait perubahan alat tangkap ikan yang ramah lingkungan.

c. Adanya campur tangan pemerintah untuk bantuan modal dan pelatihan pengoperaian alat tangkap yang lain.

\section{DAFTAR PUSTAKA}

Badan Karantina Ikan Pengendalian Mutu dan Keamanan Hasil Perikanan.

Tasiun KIPM Kelas II Tarakan.

http://tarakanbkipm.blogspot.com/2011/09/edwardsiella-tarda.html

Beye, 2016. Pelarangan Alat Tangkap Cantrang di Kalangan Nelayan Tradisional. Artikel Hukum Perikanan. ITS. Surabaya

Fauzi A. 2005. Kebijakan Perikanan dan Kelautan Issue, Sintesis, dan Gagasan. Jakarta: PT Gramedia Pustaka Utama.

Helmi A, Satria A. 2012. Strategi Adaptasi Nelayan Terhadap Perubahan Ekologi. Makara, Sosial Humaniora Vol 16 No 1 (Juli): 68-78. Diunduh di http://hubsasia.ui.ac.id/index.php/hubsasia/article/download/1494/38

Peraturan Menteri Kelautan Dan Perikanan Republik Indonesia Nomor Per.71/Men.KP/2016 Tentang tentang Jalur Penangkapan Ikan dan Penempatan Alat Penangkapan Ikan di Wilayah Pengelolaan Perikanan Negara Republik Indonesia

Radarwati S, Basoro MS, Monintja DR, Purbayanto A. 2010. Alokasi Optimum dan Wilayah Pengembangan Berbasis Alat Tangkap Potensial Teluk Jakarta. Marine Fisheries 1(2): 189-198

Rusmilyansari, 2012. Inventarisasi Alat Tangkap Berdasarkan Kategori Status Penangkapan Ikan Yang Bertanggung Jawab Di Perairan Tanah Laut. Fish Scientiae, Volume 2 No. 4. hal. 143-153

Satria A. 2009. Pesisir dan Laut untuk Rakyat. Bogor: IPB Press

Satria A, Anggraini E, Solihin A. 2009. Globalisasi Perikanan: Reposisi Indonesia?. Bogor: PT Penerbit IPB Press

Satria Arif dan Maya Resty Andryana, 2016. Dampak Pelarangan Cantrang bagi Nelayan. Laporan Studi Pustaka (KPM 403). Departemen Sains Komunikasi dan Pengembangan Masyarakat Fakultas Ekologi Manusia Institut Pertanian Bogor, 2016

Subani, W dan H.R. Barus, 1989. Alat Penangkapan Ikan Dan Udang Laut Di Indonesia. Balai Penelitian Dan Pengembangan Pertanian. Departemen Pertanian. Jakarta.

Sugiono, (2011). Metode Penelitian Pendidikan ( Pendekatan Kuantitatif, Kualitatif, dan R\&D); Alfabeta. Bandung

Sukmawati D. 2008. Struktur dan Pola Hubungan Sosial Ekonomi Juragan dengan Buruh di Kalangan Nelayan Pantai Utara Jawa Barat (Studi tentang 
Simbiosis antara Juragan dengan Nelayan Buruh di Pondok Bali Kecamatan Legon Kulon Kabupaten Subang). Jurnal Kependudukan Padjadjaran Vol 10 (1):50-63.

http://jurnal.unpad.ac.id/kependudukan/article/download/doc5/2438

Taurusman AA. 2007. Community structure, clearance rate and carrying capacity of makrozoobenthos in relation to organic matter in Jakarta Bay and Lampung Bay, Indonesia [PhD Disertation]. Kiel University. Germany. $181 \mathrm{p}$ 